Check for updates

Cite this: RSC Adv., 2017, 7, 47017

\title{
Detailed molecular movements during poly(L-lactic acid) cold-crystallization investigated by FTIR spectroscopy combined with two-dimensional correlation analysis $\uparrow$
}

\begin{abstract}
Bai Xue, ${ }^{a}$ Lan Xie (D) *a and Junhua Zhang (D) *b
A good understanding of the detailed molecular movements of the poly(L-lactic acid) (PLLA) coldcrystallization is significant for academic investigation and commercial application. In this article, the cold-crystallization process of PLLA was successfully investigated via temperature-dependent FTIR spectroscopy combined with the perturbation correlation moving-window two-dimensional (PCMW2D) spectroscopy and generalized two-dimensional correlation (2D) spectroscopy. PCMW2D reveals that the cold-crystallization of PLLA undergoes two processes: Process I $\left(60.8-73.7^{\circ} \mathrm{C}\right.$ ) and Process II $\left(91.1-104.0{ }^{\circ} \mathrm{C}\right.$ ), which is consistent with the results of differential scanning calorimetry (DSC) measurement. The method of estimating the regularization enthalpy of function groups $\left(\mathrm{CH}_{3}, \mathrm{C}=\mathrm{O}\right.$, and $\mathrm{CCO}-\mathrm{O}$ ) during both Process I and Process II is established based on van't Hoff plots. The results show that the enthalpy of the regularization of chain segments is decreased with the increasing mobility. The sequential order of the groups' movement in both Process I and Process II is successfully investigated by the generalized 2D correlation analysis, which has great significance for understanding the detailed microdynamics mechanism of the PLLA cold-crystallization. Process I is the relaxation process, which undergoes 2 steps and Process II is the primary cold-crystallization process, which has 5 steps.
\end{abstract}

Received 12th August 2017 Accepted 29th September 2017

DOI: 10.1039/c7ra08921j

rsc.li/rsc-advances interactions between the methyl groups. Eling et $a l^{4}{ }^{4}$ first determined the $\beta$ modification of PLLA which developed upon mechanical stretching of $\alpha$ crystalline or from solutionspinning processes at higher drawing temperatures and/or higher hot-draw ratio. A third $\gamma$ crystal modification of PLLA growing upon epitaxial crystallization on hexamethylbenzene substrate has two antiparallel helices in an orthorhombic unit cell with $a=0.99 \mathrm{~nm}, b=0.63 \mathrm{~nm}$, and $c=0.88 \mathrm{~nm}$, which was recently described by Cartier et al..$^{5}$ Very recently, Zhang and coworkers ${ }^{6-9}$ proposed that another new crystal modification named $\alpha^{\prime}$ form (disorder $\alpha$ form) is likely to be crystallized below $120^{\circ} \mathrm{C}$ in PLLA, different from the order $\alpha$ form crystallized at the temperature above $120{ }^{\circ} \mathrm{C}$, which has been confirmed on the basis of infrared spectroscopy and X-ray data.

It's well known that Fourier transform infrared spectroscopy (FTIR) is sensitive to the local molecular environment and the conformation of polymer chains. Therefore, FTIR spectroscopy has been widely applied to elucidate structural variations of macromolecules during the melt or crystallization process. ${ }^{10,11}$ Nevertheless, the spectra of PLLA especially in the region of $1300-1000 \mathrm{~cm}^{-1}$ associated with ester groups are greatly overlapped and the detailed analysis of PLLA FTIR spectra is very difficult to be performed. Generalized 2D correlation spectroscopy first proposed by Noda in $1993^{12}$ is a powerful and versatile tool to find the subtle spectral changes due to the significant 
enhancement of the spectral resolution compared with that of the corresponding one-dimensional spectroscopy by spreading highly overlapped spectral peaks along the second dimension. It emphasizes spectral features and probes the sequential order of spectral variables occurring under the influence of a controlled physical variable. Thus, generalized 2D correlation FTIR spectroscopy has gained popularity in investigating the complex physical or chemical transition processes of polymers. Zhang et al. ${ }^{7,8}$ reported the isothermal crystallization behaviors of PLLA from the glassy and melt states which were investigated via FTIR spectroscopy combined with generalized 2D correlation spectroscopy. The isothermal cold-crystallization was carried out at $78^{\circ} \mathrm{C}$ from amorphous state, while the isothermal melt-crystallization was monitored at $150{ }^{\circ} \mathrm{C}$ from melt state. Amazingly, significant differences were detected between the spectral changes during the isothermal cold- and meltcrystallization processes of PLLA, which illustrated that different crystal modifications might have been formed.

Moving-window two-dimensional (MW2D) correlation spectroscopy extended from generalized 2D correlation spectroscopy using the data subdivision technique was first proposed by Thomas and Richardson in $2000 .{ }^{13}$ MW2D correlation spectrum is plotted as a $2 \mathrm{D}$ contour map between a spectral variable axis and a perturbation variable axis. In 2006, Morita et al. ${ }^{\mathbf{1 4}}$ proposed the concept of perturbation-correlation movingwindow two-dimensional (PCMW2D) correlation spectroscopy which was based on generalized 2D correlation spectroscopy and MW2D correlation spectroscopy. For PCMW2D correlation spectroscopy, a pair of synchronous and asynchronous contour maps are plotted on a 2D plane defined by the perturbation variable axis (here, temperature) and spectral variable axis (here, wavenumber). The synchronous and asynchronous PCMW2D correlation intensities correspond to the spectral gradient and negative rate of spectral gradient change along the perturbation variable axis, respectively, which results in that the spectral correlation intensity variations along both spectral variable axis and perturbation variable axis can be more easily visualized.

Recently, the isothermal cold-crystallization, isothermal melt-crystallization, crystal modifications, thermal behavior, conformational behavior, glass transition behavior, and crystallization dynamics of PLLA have been widely investigated by FTIR spectroscopy. ${ }^{5-10,15-18}$ However, the detailed molecular movement during PLLA cold-crystallization process has been rarely reported. In the present study, the cold-crystallization process of PLLA was successfully investigated via the temperature-dependent FTIR spectroscopy combined with PCMW2D correlation spectroscopy and generalized 2D correlation spectroscopy. The regularization enthalpies of the chemical groups during both Process I and Process II were estimated via van't Hoff plots. The detailed molecular movement during the cold-crystallization process was successfully determined by powerful generalized $2 \mathrm{D}$ correlation analysis, which was significant for understanding the detail microdynamics mechanism of the PLLA cold-crystallization and optimizing the application of PLLA.

\section{Experimental}

\subsection{Materials}

Poly(L-lactic acid) (PLLA) with the trade mark of 4032D used in the present study was obtained from Nature Works LLC (America). PLLA in a pellet form presents a density of $1.24 \mathrm{~g} \mathrm{~cm}^{-3}$ and molecular mass $M_{\mathrm{w}} \approx 207 \mathrm{kDa}$. Analytically pure chloroform utilized as the solvent of PLLA was purchased from Chengdu Kelong Chemical Reagent Company (China).

\subsection{FTIR spectroscopy}

The film sample of PLLA for FTIR spectroscopy was obtained by solvent casting from $1 \mathrm{wt} \%$ chloroform solution. The film was dried at room temperature for $6 \mathrm{~h}$ to evaporate the majority of the solvent and then placed in a vacuum oven at $40{ }^{\circ} \mathrm{C}$ for $48 \mathrm{~h}$ to completely remove the residual solvent. A Nicolet iS10 FTIR spectrometer equipped with a deuterated triglycine sulfate (DTGS) detector was applied to perform the FTIR measurement. In order to collect FTIR spectra of PLLA with the incremental temperature, the film sample should be put into a homemade variable-temperature cell during the measurement. The PLLA film was heated from $20{ }^{\circ} \mathrm{C}$ to $220{ }^{\circ} \mathrm{C}$ at a heating rate of $5{ }^{\circ} \mathrm{C}$ min. A total of 95 FTIR spectra were recorded from 20 scans with a resolution of $4 \mathrm{~cm}^{-1}$ in the range of $4000-500 \mathrm{~cm}^{-1}$ during the heating process.

\subsection{Two-dimensional correlation analysis}

PCMW2D and generalized 2D correlation FTIR spectroscopies were carried out and plotted by a $2 \mathrm{D}$ correlation spectroscopy software (2DCS 4.0), developed by Zhou. ${ }^{19}$ The intensity of each FTIR spectrum was normalized by dividing the average value of intensity before performing $2 \mathrm{D}$ correlation analysis. A window size of $2 m+1=11$ was chosen for PCMW2D analysis in the calculation. The $5 \%$ autocorrelation intensity was regarded as noise and cut off. In both PCMW2D and generalized 2D correlation spectra, the blue areas represent negative correlation intensity, while the pink ones represent positive correlation intensity. The characteristics of the spectral variation along the perturbation variables' direction can be easily observed in the 2D maps, which illustrates that 2D correlation spectroscopies are powerful in finding hidden, weak or overlapped peaks along the spectral direction. ${ }^{20}$

\subsection{Differential scanning calorimetry}

DSC measurement of PLLA film prepared from the solventcasting method was performed on a differential scanning calorimeter (DSC-204, Netzsch, Germany). The sample of 7-8 $\mathrm{mg}$ was placed in an aluminum sample pan. And then the sample was scanned from $20{ }^{\circ} \mathrm{C}$ to $220{ }^{\circ} \mathrm{C}$ at a heating rate of $5{ }^{\circ} \mathrm{C}$ min, under a nitrogen gas flow of $40 \mathrm{ml} \mathrm{min}^{-1}$.

\section{Results and discussion}

PLLA is a semicrystalline biopolymer with a relatively low crystallization rate. ${ }^{9}$ The FTIR spectral changes of the common PLLA sample without melt-quenching or annealing in the 
wavenumber regions of $3100-2650 \mathrm{~cm}^{-1}, 1850-1700 \mathrm{~cm}^{-1}$, $1500-1000 \mathrm{~cm}^{-1}$, and $970-850 \mathrm{~cm}^{-1}$ during the heating process from $20{ }^{\circ} \mathrm{C}$ to $220{ }^{\circ} \mathrm{C}$ are shown in Fig. 1 and 2. All the four regions of FTIR spectra corresponding to $\mathrm{C}-\mathrm{H}$ stretching vibration $\left(3100-2800 \mathrm{~cm}^{-1}\right), \quad \mathrm{C}=\mathrm{O}$ stretching vibration (1800-1700 $\left.\mathrm{cm}^{-1}\right), \mathrm{CH}_{3}, \mathrm{CH}$ bending and C-O-C stretching (1500-1000 $\mathrm{cm}^{-1}$ ), and the skeletal stretching and $\mathrm{CH}_{3}$ rocking $\left(970-850 \mathrm{~cm}^{-1}\right)$ are very sensitive to the structural changes occurring in the cold-crystallization process. Nevertheless, several characteristic bands are heavily overlapped or relatively very weak, which limits the application of FTIR spectra on the investigation of PLLA melting or crystallization behaviors. PCMW2D correlation spectroscopy is a powerful tool to find the weak, hidden, or overlapped peaks. Moreover, PCMW2D can be easily utilized to determine the temperature regions of polymer transitions.

\subsection{Temperature regions determined by PCMW2D and DSC}

Fig. 3 illustrates the PCMW2D correlation FTIR spectra of PLLA in the wavenumber region of $1899-1650 \mathrm{~cm}^{-1}$, calculated from the spectra in Fig. 1. The PCMW2D correlation FTIR spectra of PLLA in the regions of $3099-2850 \mathrm{~cm}^{-1}, 1549-1300 \mathrm{~cm}^{-1}, 1301-$ $1052 \mathrm{~cm}^{-1}$, and $996-850 \mathrm{~cm}^{-1}$ are shown in Fig. S1 and S2. $\dagger$ PCMW2D spectra consist of synchronous (on the top) and asynchronous (on the bottom) correlation spectra. The pink areas represent positive correlation intensity and on the contrary, the blue areas represent negative correlation intensity. In the synchronous correlation spectra, the positive correlation intensity reveals the increasing of the absorbance intensity at a given wavenumber in the temperature-dependent FTIR spectra, and vice versa. ${ }^{21}$ For the synchronous spectra in all the wavenumber regions, the correlation bands are mainly observed in three temperature regions which are defined as Process I, Process II, and Process III. Process I is centered at $69.5{ }^{\circ} \mathrm{C}$ (slightly higher than the glass-transition temperature $\left(T_{\mathrm{g}}\right)$ ), Process II is observed at $99.6{ }^{\circ} \mathrm{C}$ (the cold-crystallization temperature $\left(T_{\mathrm{cc}}\right)$ ), and Process III is centered at $168.5{ }^{\circ} \mathrm{C}$ (the melting temperature $\left.\left(T_{\mathrm{m}}\right)\right)$. In this article, we focus our interests on the cold-crystallization of PLLA (Process I and Process II).

3.1.1 Process I. In the synchronous spectra, the band at $921 \mathrm{~cm}^{-1}$ well assigned to the coupling of C-C backbone stretching with $\mathrm{CH}_{3}$ rocking mode and sensitive to the $10_{3}$ helix chain conformation presents a negative correlation peak. ${ }^{6,7}$ When the polymer sample is obtained by solvent casting, polymer chain mobility is largely decreased with the volatilization of solvent and the material becomes a thermodynamically unstable state. While such sample is heated to $T_{\mathrm{g}}$, the mobility of chain segments increases enough to reach the thermodynamically stable state. Thus the random packed $10_{3}$ helical chain frozen in the glassy state could be relaxed or melted above
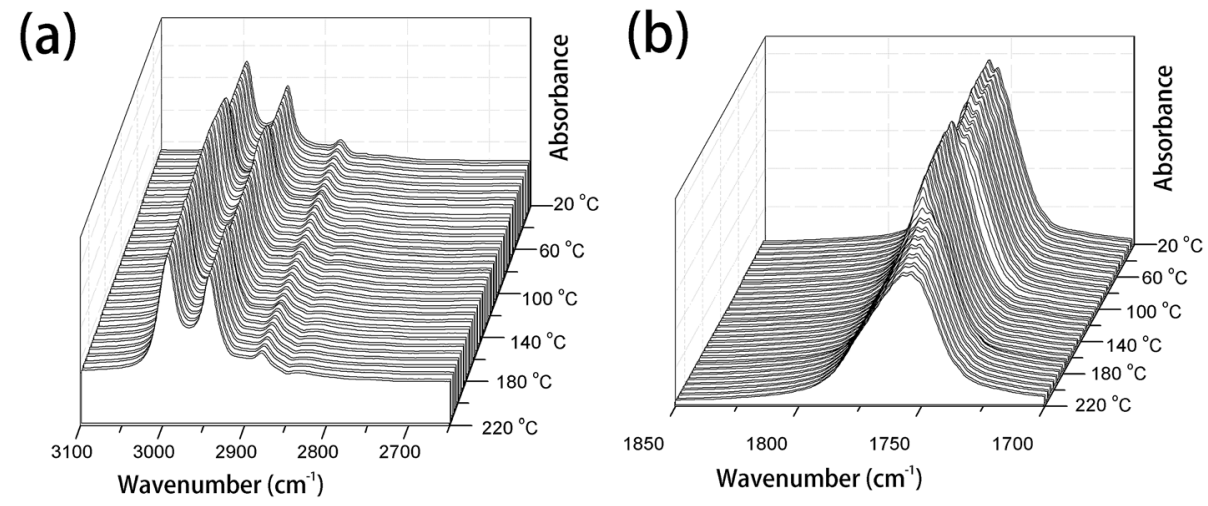

Fig. 1 The temperature-dependent FTIR spectra of PLLA upon heating from $20{ }^{\circ} \mathrm{C}$ to $220{ }^{\circ} \mathrm{C}$, (a) $3100-2600 \mathrm{~cm}^{-1}$ and (b) $1850-1700 \mathrm{~cm}^{-1}$.
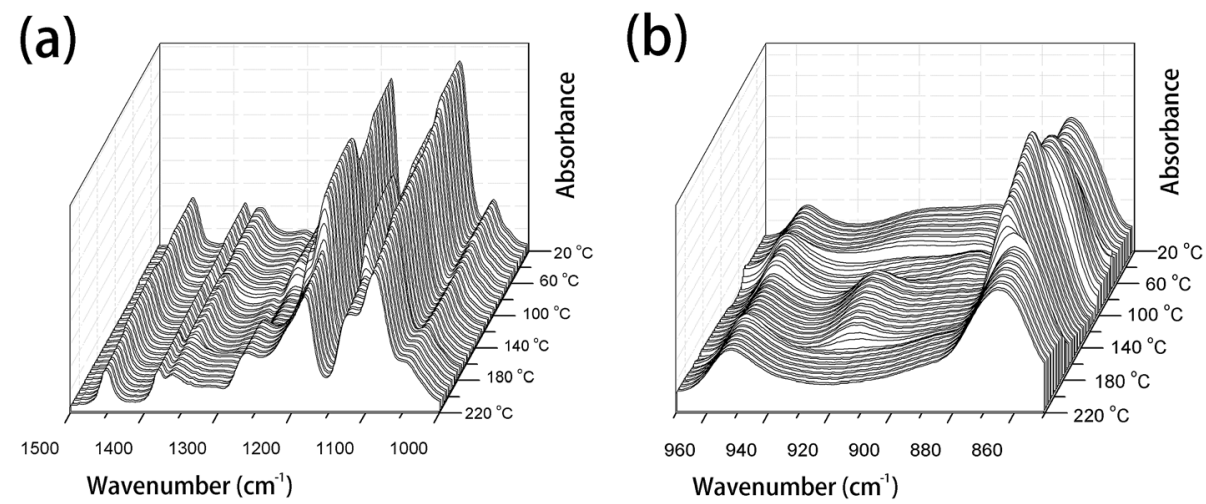

Fig. 2 The temperature-dependent FTIR spectra of PLLA upon heating from $20^{\circ} \mathrm{C}$ to $220^{\circ} \mathrm{C}$, (a) $1500-1000 \mathrm{~cm}^{-1} \mathrm{and}^{(\mathrm{b})} 970-850 \mathrm{~cm}^{-1}$. 


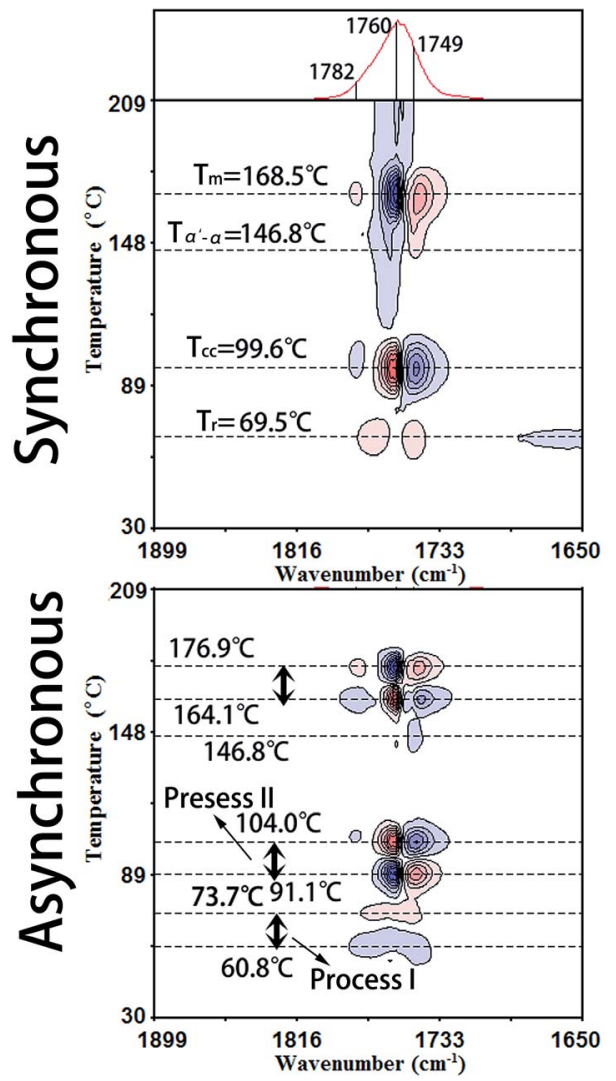

Fig. 3 PCMW2D correlation FTIR spectra of PLLA in the region of $1899-1650 \mathrm{~cm}^{-1}$ calculated from the temperature-dependent spectroscopy. The blue areas represent negative correlation intensity and the pink areas represent positive correlation intensity.

the glass transition. ${ }^{9}$ The band at $955 \mathrm{~cm}^{-1}$ ascribed to the amorphous phase also shows a negative correlation peak in the synchronous spectra. This illustrates that the amorphous phase of PLLA is transformed into order phase or semiorder phase with the increasing temperature in Process I. The bands of $1453 \mathrm{~cm}^{-1}$ and $1384 \mathrm{~cm}^{-1}$ corresponding to the $\mathrm{CH}_{3}$ asymmetric and symmetric deformation show positive correlation peaks in the synchronous spectra, which indicates that the mobility of $\mathrm{CH}_{3}$ groups is heavily increased at the temperature higher than $T_{\mathrm{g}}$ and the relaxation of polymer chains is largely accelerated. ${ }^{22,23}$ The bands of $2995 \mathrm{~cm}^{-1}$ and $2945 \mathrm{~cm}^{-1}$ attributed to the asymmetric and symmetric stretching modes of $\mathrm{CH}_{3}$ groups present intense positive correlation peaks, which is consistent with the $\mathrm{CH}_{3}$ deformation bands. In the synchronous spectra, the $\mathrm{C}=\mathrm{O}$ stretching bands of $1790-1730 \mathrm{~cm}^{-1}$ show two positive correlation peaks at $1768 \mathrm{~cm}^{-1}$ and $1749 \mathrm{~cm}^{-1}$ which have been assigned to tg $\left(5_{1}\right)$ and tt $\left(2_{1}\right)$ conformers in the interphase by Sarasua et al. ${ }^{24}$ The crystalline phase, the interphase, and the amorphous phase are three phases discerned in the switchboard crystallization pattern, according to traditional crystallization theories. The interphase is considered as a transition phase between crystalline and amorphous phases and it is a metastable state with a typical thickness of $1-2 \mathrm{~nm}^{24}$ The interphase of PLLA is largely increased with the incremental temperature in Process I.
No obvious correlation peaks are observed in the synchronous spectrum in the wavenumber region of $1300-1000 \mathrm{~cm}^{-1}$, which is mainly corresponding to the stretching vibration of $\mathrm{C}-\mathrm{O}-\mathrm{C}$ backbone and rocking of $\mathrm{CH}_{3}$. The most probable reason is that the mobility of the polymer backbone is much lower than that of side groups and the relaxation of backbone is much slower. Therefore the structural change of the PLLA backbone is very slight with the increasing temperature in Process I. The asynchronous spectra could be easily applied to determine the temperature regions of polymer transitions. ${ }^{21,25}$ As shown in Fig. 3, the temperature region of Process I for all the characteristic PLLA bands is accurately determined within $60.8-73.7^{\circ} \mathrm{C}$.

3.1.2 Process II. In the synchronous spectra, the band of $921 \mathrm{~cm}^{-1}$ sensitive to the $10_{3}$ helix chain conformation shows a very intense positive correlation peak. $955 \mathrm{~cm}^{-1}$ attributed to the amorphous phase presents a stronger negative correlation peak than that of Process I. In Process II, the crystallinity degree of PLLA is rapidly increased with the incremental temperature, thus the content of regular phase, especially the helical chain, is largely increased. Moreover, the spectral band splitting phenomenon of PLLA is clearly observed with the coldcrystallization in Process II. The band splittings, the band assignments and the corresponding explanations are listed in Table 1. For example, the band at $1454 \mathrm{~cm}^{-1}$ corresponding to the $\mathrm{CH}_{3}$ asymmetric deformation splits into two bands at 1458 and $1442 \mathrm{~cm}^{-1}$ with the evolution of the crystallization. Another band at $1362 \mathrm{~cm}^{-1}$ assigned to $\delta_{\mathrm{s}}\left(\mathrm{CH}_{3}\right)+\delta(\mathrm{CH})$ turns into two bands at 1368 and $1359 \mathrm{~cm}^{-1}$ which should be related to the structural order of methyl groups in the crystalline phase during the cold-crystallization of PLLA. Polymers not only present resonance splitting of bands associated with interaction between analogous groups along the polymer chain but also exhibit splitting of certain vibrations due to intramolecular interaction of the helical chains. Sarasua et al. ${ }^{11,26}$ had reported that intramolecular coupling, factor group splitting, and crystal orientation could explain all the spectral features observed in crystalline PLLA. According to the asynchronous spectra, the temperature region of Process II is accurately determined within $91.1-104.0{ }^{\circ} \mathrm{C}$. It is noticed to us that several weak correlation peaks are observed around $146.8{ }^{\circ} \mathrm{C}$, which demonstrate that the disordered $\alpha\left(\alpha^{\prime}\right)$ phase formed during the cold-crystallization process is transformed to more stable $\alpha$ phase just before the melting of PLLA., ${ }^{8,9}$

To further determine the temperature regions of PLLA heating process, differential scanning calorimetry (DSC) measurement was carried out with the PLLA film sample obtained via solution casting. The heating DSC curve is shown in Fig. 4. An endothermic peak is observed at $61.8^{\circ} \mathrm{C}$ near the glass-transition temperature $\left(T_{\mathrm{g}}=53.4^{\circ} \mathrm{C}\right)$ because of physical aging of the polymer materials. ${ }^{27}$ There are chain segment relaxations for both the regular helical conformation and the irregular chain conformation. When the PLLA sample is reheated above $T_{\mathrm{g}}$, chain segments are active enough to adjust themselves for reaching the more stable and regular conformation. 
Table 1 Band assignments of the vibration modes in Process I and II $^{a}$

\begin{tabular}{|c|c|c|c|}
\hline \multicolumn{2}{|c|}{ FTIR wavenumber $\left(\mathrm{cm}^{-1}\right)$} & \multirow[b]{2}{*}{ Assignments } & \multirow[b]{2}{*}{ Explanations } \\
\hline Process I & Process II & & \\
\hline $2995 \uparrow$ & $\{3005 \uparrow,\{2990 \downarrow$ & $\nu_{\mathrm{as}}\left(\mathrm{CH}_{3}\right)$ & \\
\hline$\{1768 \uparrow,\{1749 \uparrow$ & $\{1782 \downarrow,\{1760 \uparrow,\{1749 \downarrow$ & $\nu(\mathrm{C}=\mathrm{O})$ & $1782 \mathrm{~cm}^{-1}$ corresponds to gg interphase, $1768 \mathrm{~cm}^{-1}$ is attribute \\
\hline $1454 \uparrow$ & $\{1458 \uparrow,\{1442 \uparrow$ & $\delta_{\mathrm{as}}\left(\mathrm{CH}_{3}\right)$ & $\begin{array}{l}\text { tg interphase, } 1760 \mathrm{~cm}^{-1} \text { is ascribed to gt crystalline and gt int } \\
1749 \mathrm{~cm}^{-1} \text { is assigned to tt interphase }\end{array}$ \\
\hline $1384 \uparrow$ & $\{1389 \uparrow,\{1379 \downarrow$ & $\delta_{\mathrm{s}}\left(\mathrm{CH}_{3}\right)$ & \\
\hline $1362 \uparrow$ & $\{1368 \uparrow,\{1359 \uparrow$ & $\delta_{\mathrm{s}}\left(\mathrm{CH}_{3}\right)+\delta(\mathrm{CH})$ & The coupling of $\mathrm{CH}_{3}$ symmetric bending with the $\mathrm{CH}$ bending \\
\hline 1212 & $\{1214 \uparrow,\{1193 \uparrow$ & $\nu_{\text {as }}(\mathrm{CCO}-\mathrm{O})+r_{\text {as }}\left(\mathrm{CH}_{3}\right)$ & The coupling of C-O-C stretching with the $\mathrm{CH}_{3}$ rocking \\
\hline $865 \uparrow$ & $\{871 \uparrow,\{860 \downarrow$ & $\nu(\mathrm{C}-\mathrm{COO})$ & $871 \mathrm{~cm}^{-1}$ band is also sensitive to the $10_{3}$ helix conformation \\
\hline
\end{tabular}

a “ $\{$ ” represents the band splitting, “ $\uparrow$ ” represents the intensity of the band increases with the increasing temperature, “ $\downarrow$ ” represents the intensity of the band decreases with the increasing temperature.

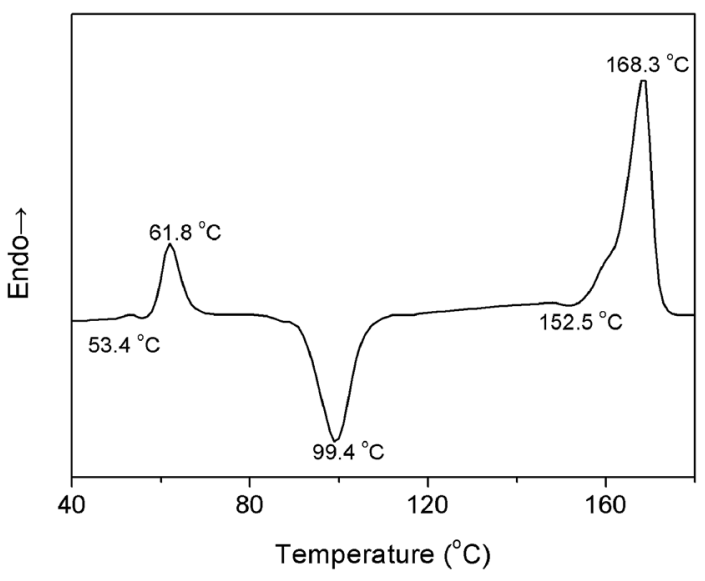

Fig. 4 DSC curve of PLLA upon heating at a heating rate of $5^{\circ} \mathrm{C} \mathrm{min}^{-1}$.

The characteristic data of PLLA, including the glasstransition temperature $\left(T_{\mathrm{g}}\right)$, the relaxation temperature $\left(T_{\mathrm{r}}\right)$, the cold-crystallization temperature $\left(T_{\mathrm{cc}}\right)$, the $\alpha^{\prime}$-to- $\alpha$ phase transition temperature $\left(T_{\alpha^{\prime}-\alpha}\right)$, the melting temperature $\left(T_{\mathrm{m}}\right)$, and the temperature regions of Process I and Process II obtained by PCMW2D and DSC, respectively, are listed in Table 2 . The results obtained from these two methods are obviously different. The most probable reasons are as follows: (1) DSC technique measures the heat flow during the heating process of PLLA, responding to the long-range chain structure, whereas the FTIR spectroscopy is sensitive to local molecular environment presenting the vibration of short-range structure. ${ }^{\mathbf{6 , 8 , 1 7}}$ (2) The heating systems control precisions in DSC and FTIR heating cell are quite different, and temperature registered in FTIR cell may lag behind the controller's reading. Although the definite reason is very complicated and ambiguous, there's no doubt that the result difference origins from the different measurement method.

\subsection{Enthalpy of the regularization of $\mathrm{CH}_{3}, \mathrm{C}=\mathrm{O}$, and $\mathrm{CCO}-\mathrm{O}$ groups}

The bands of $921 \mathrm{~cm}^{-1}$ and $955 \mathrm{~cm}^{-1}$ are well separated in the FTIR spectra (Fig. 2), therefore, these two bands are possible to quantitatively determine the crystallinity of PLLA. ${ }^{11,15}$ Sarasua et $a l .{ }^{11}$ reported that the PLLA crystallinity was easily calculated from the percent area loss of the band at $955 \mathrm{~cm}^{-1}$. In this paper, the modified formula is shown as follows:

$$
X_{\mathrm{o}}=\frac{I_{\mathrm{m}}-I_{\mathrm{T}}}{I_{\mathrm{m}}} \times 100 \%
$$

where $X_{\mathrm{o}}$ stands for the ordering degree of PLLA, which is the content of the regular conformation in PLLA, $I_{\mathrm{T}}$ is the intensity of the band of $955 \mathrm{~cm}^{-1}$ at a given temperature, and $I_{\mathrm{m}}$ denotes the intensity of $955 \mathrm{~cm}^{-1}$ at the PLLA melting state (at $220^{\circ} \mathrm{C}$ ).

Fig. 5(a) and (b) show the intensity of the band at $955 \mathrm{~cm}^{-1}$ and the ordering degree as a function of temperature, respectively. It is clearly observed that the ordering degree is decreasing with the increasing temperature below $60.4{ }^{\circ} \mathrm{C}$, which is mainly ascribed to the temperature effect. The first abrupt increase of the ordering degree is observed in the temperature region of $60.8-77.3{ }^{\circ} \mathrm{C}$, corresponding to Process I. The most probable reason is that the relaxation of chain segments is largely accelerated and the mobility is increased above $T_{\mathrm{g}}$. Polymer chain segments are active enough to adjust themselves for reaching the more stable interphase whose ordering degree is much higher than that of amorphous phase. The second abrupt increase is shown in the temperature range from 90.1 to $104.0^{\circ} \mathrm{C}$, corresponding to Process II. The ordering degree with the highest value of $40.6 \%$ is obtained at $104.0{ }^{\circ} \mathrm{C}$.

Table 2 The $T_{\mathrm{g}}, T_{\mathrm{r}}, T_{\mathrm{cc}}, T_{\alpha^{\prime}-\alpha,} T_{\mathrm{m}}$ and the temperature regions of Process I and Process $\|$ obtained from PCMW2D and DSC measurements

\begin{tabular}{|c|c|c|c|c|c|c|c|}
\hline & $T_{\mathrm{g}}\left({ }^{\circ} \mathrm{C}\right)$ & $T_{\mathrm{r}}\left({ }^{\circ} \mathrm{C}\right)$ & $T_{\text {cc }}\left({ }^{\circ} \mathrm{C}\right)$ & $T_{\alpha^{\prime}-\alpha}\left({ }^{\circ} \mathrm{C}\right)$ & $T_{\mathrm{m}}\left({ }^{\circ} \mathrm{C}\right)$ & Process I $\left({ }^{\circ} \mathrm{C}\right)$ & Process II $\left({ }^{\circ} \mathrm{C}\right)$ \\
\hline PCMW2D & - & 69.5 & 99.6 & 146.8 & 168.5 & $60.8-73.7$ & $91.1-104.0$ \\
\hline DSC & 53.4 & 61.8 & 99.4 & 152.5 & 168.3 & $57.1-70.8$ & $89.1-110.7$ \\
\hline
\end{tabular}


(a)
During this temperature region, PLLA is rapidly coldcrystallized, therefore, the ordering degree of PLLA is largely increased. A large decrease of ordering degree is presented in the temperature region of $162.3-177.2{ }^{\circ} \mathrm{C}$, corresponding to the melting process of PLLA. The ordering degree continuously decreases above $177.2{ }^{\circ} \mathrm{C}$ due to the temperature effect.

As shown in Fig. 6, the intensities of the bands at 1760, 1458, 1193 , and $1133 \mathrm{~cm}^{-1}$, which are ascribed to $\nu(\mathrm{C}=\mathrm{O}), \delta_{\mathrm{as}}\left(\mathrm{CH}_{3}\right)$, $\nu_{\text {as }}(\mathrm{CCO}-\mathrm{O})+r_{\mathrm{as}}\left(\mathrm{CH}_{3}\right)$, and $r_{\mathrm{s}}\left(\mathrm{CH}_{3}\right)$, respectively, increase with the incremental temperature during the PLLA primary coldcrystallization process (Process II, 91.1-104.0 ${ }^{\circ} \mathrm{C}$ ). These bands have been previously assigned to crystalline sensitive bands. ${ }^{6-8,15}$ However, the intensities of these bands also increase with the incremental temperature during the relaxation process

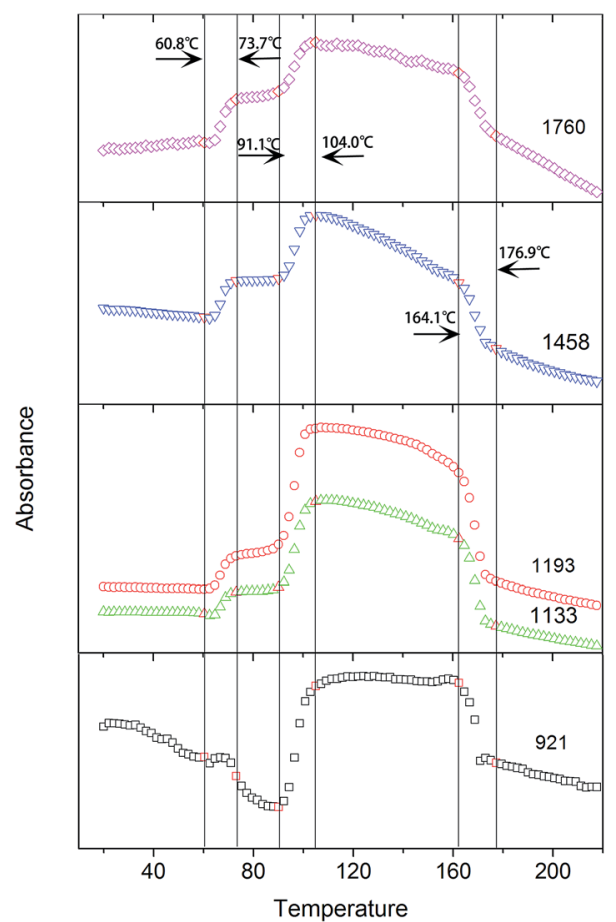

Fig. 6 Intensities of the bands at $1760 \mathrm{~cm}^{-1}, 1458 \mathrm{~cm}^{-1}, 1193 \mathrm{~cm}^{-1}$, $1133 \mathrm{~cm}^{-1}$, and $921 \mathrm{~cm}^{-1}$ as a function of temperature.
(Process I, 60.8-73.7 ${ }^{\circ} \mathrm{C}$ ). Another band at $921 \mathrm{~cm}^{-1}$, which is also increased during the cold-crystallization process, has been successfully assigned to the $10_{3}$ helical chain conformation existing in both the crystalline and amorphous phase.,11,24 Therefore, the bands at $1760,1458,1193$, and $1133 \mathrm{~cm}^{-1}$ are more rational to be determined as regular conformation sensitive bands rather than crystalline sensitive bands. The ordering degree of function groups $\left(\mathrm{C}=\mathrm{O}, \mathrm{CH}_{3}\right.$, and $\left.\mathrm{CCO}-\mathrm{O}\right)$ is largely increased with the increasing temperature in both Process I and Process II. The enthalpy of the regularization of these groups can be calculated according to the intensity of the characteristic FTIR bands.

The regularization of groups in PLLA chains can be considered as an equilibrium reaction, which is expressed as follows:<smiles>CCC(=O)C(C)OC</smiles><smiles>COCC(C)=O</smiles>

( amorphous phase) $\left(1-a_{r}\right) C_{0}$ where $C_{0}$ is the total molar concentration of regular chemical groups, when PLLA is fully crystallized. $\alpha_{\mathrm{r}}$ stands for the molar fraction of regular chemical groups at a given temperature.

$$
C_{0}=C_{104} / \chi
$$

where $C_{104}$ represents the molar concentration of regular chemical groups for PLLA at $104.0^{\circ} \mathrm{C}$. $\chi$ with the value of $40.6 \%$ is the ordering degree of the PLLA sample at $104.0^{\circ} \mathrm{C}$.

According to the Beer-Lambert law, ${ }^{28}$ the relationship between absorbance $A$ and the molar concentration $C$ can be expressed as the following equations:

$$
\begin{gathered}
A_{0}=\varepsilon L C_{0} \\
A_{104}=\varepsilon L C_{104} \\
A_{\mathrm{r}}=\varepsilon L C_{\mathrm{r}}
\end{gathered}
$$


where $\varepsilon$ is the extinction coefficients of the regular chemical groups, $L$ denotes the optical path of the sample. $A_{0}, A_{104}$, and $A_{\mathrm{r}}$ are the absorbance of the characteristic FTIR peak when PLLA is fully crystallized, at $104.0{ }^{\circ} \mathrm{C}$ and at a given temperature, respectively.

The molar fraction of the regular chemical groups $\left(\alpha_{\mathrm{r}}\right)$ can be calculated from the equation:

$$
\alpha_{\mathrm{r}}=\frac{C_{\mathrm{r}}}{C_{0}}=\frac{\chi C_{\mathrm{r}}}{C_{104}}=\frac{\chi A_{\mathrm{r}} / \varepsilon L}{A_{104} / \varepsilon L}=\frac{\chi A_{\mathrm{r}}}{A_{104}}
$$

The molar fraction of the amorphous chemical groups $\left(\alpha_{\mathrm{a}}\right)$ can be expressed as:

$$
\alpha_{\mathrm{a}}=1-\alpha_{\mathrm{r}}
$$

The equilibrium constant $(K)$ can be expressed as:

$$
K=\frac{\alpha_{\mathrm{r}} C_{0}}{\left(1-\alpha_{\mathrm{r}}\right) C_{0}}=\frac{\alpha_{\mathrm{r}}}{\left(1-\alpha_{\mathrm{r}}\right)}
$$

Eqn (9) can be transformed into the van't Hoff form:

$$
\ln K=\ln \left[\frac{\alpha_{\mathrm{r}}}{\left(1-\alpha_{\mathrm{r}}\right)}\right]=-\frac{\Delta H}{R} \times \frac{1}{T}+\frac{\Delta S}{R}
$$

where $\Delta H$ is the enthalpy of the regularization of chemical groups, $R$ is the gas constant with the value of $8.314 \mathrm{~J} \mathrm{~mol}^{-1} \mathrm{~K}^{-1}$, $T$ stands for the absolute temperature in kelvin, and $\Delta S$ $\left(\mathrm{J} \mathrm{mol}^{-1} \mathrm{~K}^{-1}\right.$ ) represents the entropy of the regularization of chemical groups.
Therefore, a straight line can be fitted from the plot between $\ln \left[\frac{\alpha_{\mathrm{r}}}{\left(1-\alpha_{\mathrm{r}}\right)}\right]$ and $1 / T$ using the line fitting. The regularization enthalpy of chemical groups could be easily estimated from the slope of the fitting line.

van't Hoff plots obtained from the temperature-dependent FTIR spectra are presented in Fig. 7. It is clearly seen that two straight lines which are rapidly decreased with the increasing value of $1 / T$ can be commendably fitted for each van't Hoff plot. These two decreasing lines are observed in the $1 / T$ regions of $2.65 \times 10^{-3}-2.75 \times 10^{-3}$ and $2.89 \times 10^{-3}-2.98 \times 10^{-3}$, corresponding to Process II and Process I, respectively. The estimated regularization enthalpies of chemical groups in Process I and II are presented in Table 3. For the regularization of the chemical groups, an endothermic process is determined owing to the positive value of the obtained enthalpy. Thus, the larger absolute value of the enthalpy indicates the more difficulty of the chemical groups regularization.

Table 3 The regularization enthalpies of the groups calculated via van't Hoff plots in Fig. 8

\begin{tabular}{llll}
\hline & & $\begin{array}{l}\text { Enthalpy of the } \\
\text { regularization } \\
\left(\mathrm{kJ} \mathrm{mol}^{-1}\right)\end{array}$ \\
\cline { 3 - 4 } & Assignments & Process I & Process II \\
\hline 1133 & $r_{\mathrm{s}}\left(\mathrm{CH}_{3}\right)$ & $17.4 \pm 2.0$ & $27.8 \pm 3.1$ \\
1193 & $\nu_{\text {as }}(\mathrm{CCO} \mathrm{O})+r_{\mathrm{s}}\left(\mathrm{CH}_{3}\right)$ & $23.4 \pm 1.8$ & $52.9 \pm 5.2$ \\
1458 & $\delta_{\text {as }}\left(\mathrm{CH}_{3}\right)$ & $16.8 \pm 1.7$ & $27.4 \pm 1.6$ \\
1760 & $\nu(\mathrm{C}=\mathrm{O})$ & $21.8 \pm 1.8$ & $29.0 \pm 2.0$
\end{tabular}
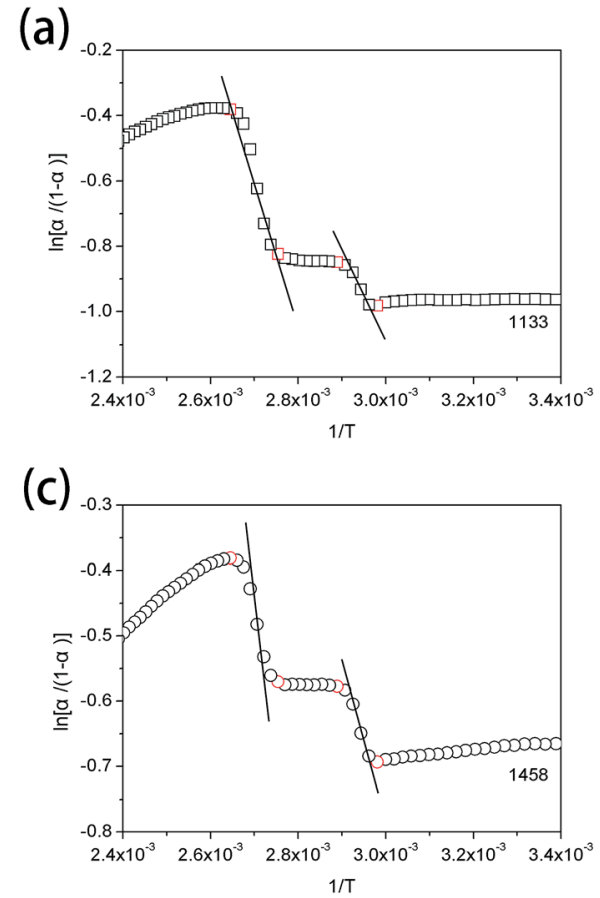

(b)

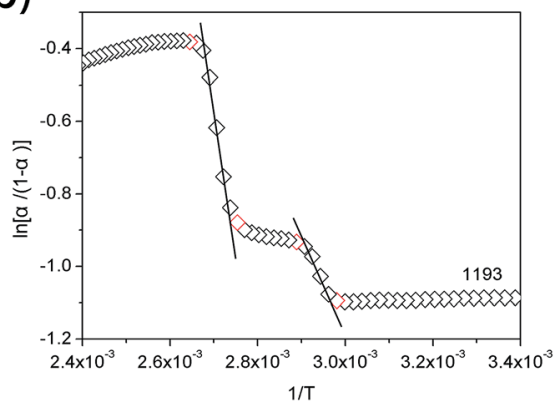

(d)

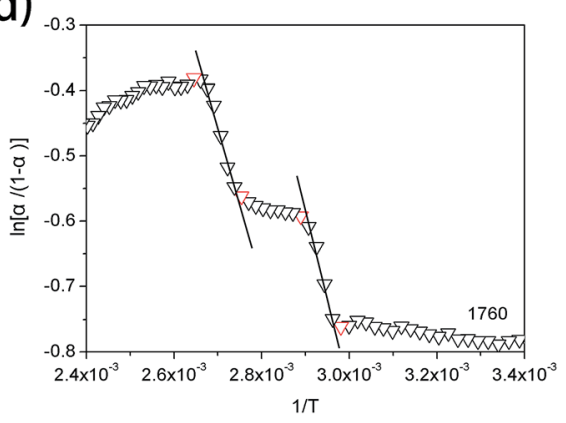

Fig. 7 van't Hoff plots from the temperature-dependent FTIR spectra of PLLA, calculating from the absorbance change at (a) $1133 \mathrm{~cm}^{-1}$, (b) $1193 \mathrm{~cm}^{-1}$, (c) $1458 \mathrm{~cm}^{-1}$ and (d) $1760 \mathrm{~cm}^{-1}$. 
During both Process I and Process II, the regularization enthalpies of $\mathrm{CH}_{3}$ group calculated from the band at $1133 \mathrm{~cm}^{-1}$ are approximately equal to the $\mathrm{CH}_{3}$ enthalpies estimated from the band at $1458 \mathrm{~cm}^{-1}$. The enthalpies of $\mathrm{C}=\mathrm{O}$ regularization are $21.8 \pm 1.8 \mathrm{~kJ} \mathrm{~mol}^{-1}$ in Process I and $29.0 \pm 2.0 \mathrm{~kJ} \mathrm{~mol}^{-1}$ in Process II, which are both larger than those of $\mathrm{CH}_{3}$ regularization. However, the regularization enthalpies of $\mathrm{CCO}-\mathrm{O}$ combined with $\mathrm{CH}_{3}$ increase to the values of $23.4 \pm 1.8 \mathrm{~kJ} \mathrm{~mol}^{-1}$ in Process I and $52.9 \pm 5.2 \mathrm{~kJ} \mathrm{~mol}^{-1}$ in Process II. This illustrates that $\mathrm{C}=\mathrm{O}$ groups can much more easily form the regular phase than CCO-O groups. Nevertheless, the regularization of $\mathrm{C}=\mathrm{O}$ is more difficult than that of $\mathrm{CH}_{3}$, which is corresponding to the mobility sequence at the same temperature: $\mathrm{CH}_{3}>\mathrm{C}=\mathrm{O}>$ CCO-O. The regularization enthalpy of chemical groups is decreased with their increasing mobility. Moreover, for all the functional groups, the regularization enthalpy is increased from Process I to Process II. The most probable reason is that the relaxation of chain segments mainly occurs in Process I and the cold-crystallization takes place in Process II. The perfection extent of the regular phase in primary cold-crystallization process (Process II) is largely higher than that in the relaxation process (Process I). Thus, the ordered arrangement of chemical groups in Process II needs more energy to reach the stable conformation.

\subsection{Generalized 2D correlation analysis}

In order to capture a detailed mechanism from the molecular movements, the temperature-dependent FTIR spectra within Process I $\left(60.8-73.7^{\circ} \mathrm{C}\right.$ ) and Process II (91.1-104.0 ${ }^{\circ} \mathrm{C}$ ) were applied to carry out the generalized $2 \mathrm{D}$ correlation analysis. The sequential order of the spectral intensity at a certain wavenumber can be easily determined by the sign of the correlation peaks, according to Noda's rule: ${ }^{\mathbf{1 2 , 2 9}}$

(1) If $\Phi\left(\nu_{1}, \nu_{2}\right)<0, \Psi\left(\nu_{1}, \nu_{2}\right)<0$ or $\Phi\left(\nu_{1}, \nu_{2}\right)>0, \Psi\left(\nu_{1}, \nu_{2}\right)>0$, then the movement of $\nu_{1}$ is before that of $\nu_{2}$.

(2) If $\Phi\left(\nu_{1}, \nu_{2}\right)<0, \Psi\left(\nu_{1}, \nu_{2}\right)>0$ or $\Phi\left(\nu_{1}, \nu_{2}\right)>0, \Psi\left(\nu_{1}, \nu_{2}\right)<0$, then the movement of $\nu_{2}$ is before that of $\nu_{1}$.
(3) If $\Phi\left(\nu_{1}, \nu_{2}\right)<0$ or $\Phi\left(\nu_{1}, \nu_{2}\right)>0, \Psi\left(\nu_{1}, \nu_{2}\right)=0$, the movements of $\nu_{1}$ and $\nu_{2}$ are simultaneous.where $\Phi\left(\nu_{1}, \nu_{2}\right)$ is the synchronous intensity and $\Psi\left(\nu_{1}, \nu_{2}\right)$ is the asynchronous intensity.

3.3.1 Process I. Fig. 8 presents the generalized 2D correlation FTIR spectra in the region $1899-1650 \mathrm{~cm}^{-1}$ vs. 1899$1650 \mathrm{~cm}^{-1}$ calculated from the temperature-dependent spectra in Process I (60.8-73.7 ${ }^{\circ} \mathrm{C}$ ) (the generalized 2D correlation FIRT spectra in the regions $1899-1650 \mathrm{~cm}^{-1}$ vs. $1549-1300 \mathrm{~cm}^{-1}$, 1899-1650 $\mathrm{cm}^{-1}$ vs. 1301-1042 $\mathrm{cm}^{-1}, 1899-1650 \mathrm{~cm}^{-1}$ vs. 996-850 cm $\mathrm{cm}^{-1}, \quad 1549-1300 \mathrm{~cm}^{-1}$ vs. $1549-1300 \mathrm{~cm}^{-1}$, 1549-1300 $\mathrm{cm}^{-1}$ vs. $1301-1042 \mathrm{~cm}^{-1}, 1549-1300 \mathrm{~cm}^{-1}$ vs. 996-850 $\mathrm{cm}^{-1}$, 1301-1042 $\mathrm{cm}^{-1}$ vs. 1301-1042 $\mathrm{cm}^{-1}$, 1301-1042 $\mathrm{cm}^{-1}$ vs. 996-850 $\mathrm{cm}^{-1}$, and $996-850 \mathrm{~cm}^{-1}$ vs. 996-850 $\mathrm{cm}^{-1}$ are shown in Fig. S4-S6 $\dagger$ ). The correlation spectra on the left represent the synchronous spectra, and those on the right are the asynchronous spectra. The blue and pink areas denote the negative and positive correlation intensity, respectively. The signs of the correlation peaks in the wavenumber region of $1899-850 \mathrm{~cm}^{-1}$ during Process I are listed in Table 4.

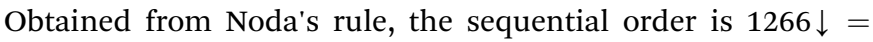
$921 \downarrow=955 \downarrow>1768 \uparrow>868 \uparrow>1454 \uparrow=1384 \uparrow>1182 \uparrow>1095 \uparrow$ $>1364 \uparrow$. In this article, the symbol “ $\uparrow$ ” represents the intensity of the band increases with the increasing temperature, “ $\downarrow$ ” represents the intensity of the band decreases with the increasing temperature. ">” represents "before", “<” represents "after", and "=" represents "simultaneous with". The corresponding sequential order of groups is $\nu_{\text {as }}(\mathrm{CCO}-\mathrm{O})+\delta(\mathrm{CH}) \downarrow=$ $r\left(\mathrm{CH}_{3}\right)+\nu(\mathrm{C}-\mathrm{C}) \downarrow>\nu(\mathrm{C}=\mathrm{O}) \uparrow>\nu(\mathrm{C}-\mathrm{COO}) \uparrow>\delta_{\text {as }}\left(\mathrm{CH}_{3}\right) \uparrow=$ $\delta_{\mathrm{s}}\left(\mathrm{CH}_{3}\right) \uparrow>\nu_{\mathrm{as}}(\mathrm{CCO}-\mathrm{O})+r_{\mathrm{as}}\left(\mathrm{CH}_{3}\right) \uparrow>\nu_{\mathrm{as}}(\mathrm{O}-\mathrm{CCO}) \uparrow>\delta_{\mathrm{s}}\left(\mathrm{CH}_{3}\right)+$ $\delta(\mathrm{CH}) \uparrow$.

The band of $1266 \mathrm{~cm}^{-1}$ has been assigned to the $\nu_{\text {as }}(\mathrm{CCO}-\mathrm{O})$ $+\delta(\mathrm{CH})$ vibration mode of the less energy-favorable gg conformer of PLLA, which is sensitive to the amorphous PLLA phase. ${ }^{30,31}$ Firstly, the random packed $10_{3}$ helical chains frozen in the glassy state are relaxed in Process I. And at the same time, the ester and methyne groups existing in the amorphous phase are decreased, which indicates that the disordered chains begin to move and rearrange. The second step is the regularization of

\section{Synchronous Asynchronous}

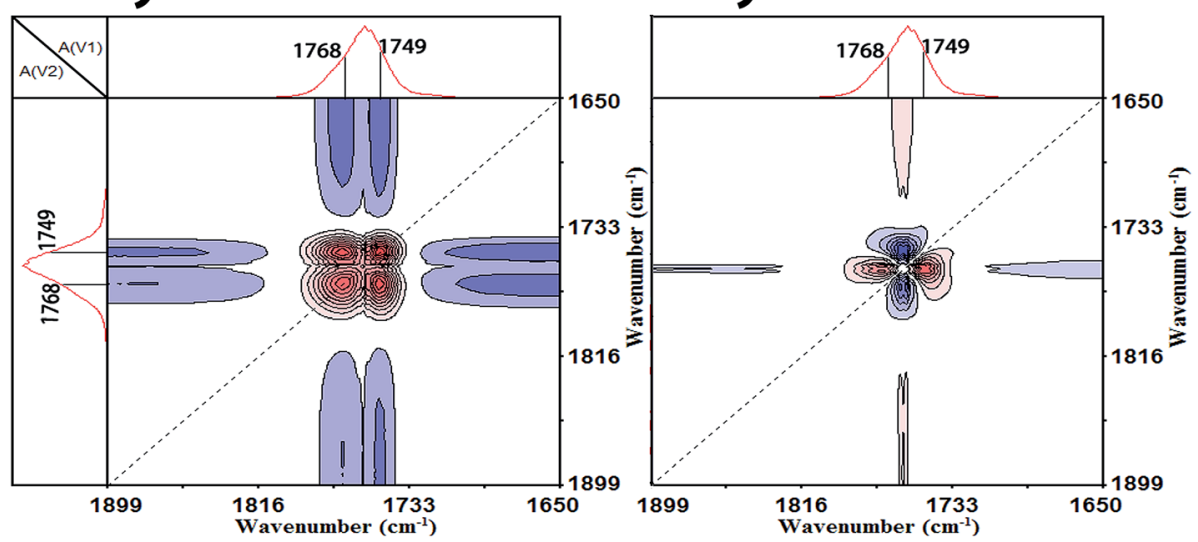

Fig. 8 Synchronous (left) and asynchronous (right) 2D correlation FTIR spectra calculated from the temperature-dependent spectra of Process I $\left(60.8-73.7^{\circ} \mathrm{C}\right)$ in the region $1899-1650 \mathrm{~cm}^{-1}$ vs. $1899-1650 \mathrm{~cm}^{-1}$. 
Table 4 Sequential order of the PLLA bands and their cross regions in Process ${ }^{a}$

\begin{tabular}{|c|c|c|c|c|c|c|c|}
\hline $\begin{array}{l}\text { Cross correlation } \\
\text { peak }\left(\mathrm{cm}^{-1}\right)\end{array}$ & $\begin{array}{l}\text { Sign in } \\
\text { synchronous } \\
\text { spectra }\end{array}$ & $\begin{array}{l}\text { Sign in } \\
\text { asynchronous } \\
\text { spectra }\end{array}$ & $\begin{array}{l}\text { Sequential } \\
\text { order }\end{array}$ & $\begin{array}{l}\text { Cross correlation } \\
\text { peak }\left(\mathrm{cm}^{-1}\right)\end{array}$ & $\begin{array}{l}\text { Sign in } \\
\text { synchronous } \\
\text { spectra }\end{array}$ & $\begin{array}{l}\text { Sign in } \\
\text { asynchronous } \\
\text { spectra }\end{array}$ & $\begin{array}{l}\text { Sequential } \\
\text { order }\end{array}$ \\
\hline$(1768,1384)$ & + & + & $1768>1384$ & $(1364,1266)$ & + & - & $1364<1266$ \\
\hline$(1768,1364)$ & + & + & $1768>1364$ & $(1364,1182)$ & + & - & $1364<1182$ \\
\hline$(1768,1266)$ & + & - & $1768<1266$ & $(1364,1095)$ & + & - & $1364<1095$ \\
\hline$(1768,955)$ & - & + & $1768<955$ & $(1364,868)$ & - & + & $1364<868$ \\
\hline$(1768,921)$ & - & + & $1768<921$ & $(1266,1182)$ & - & - & $1266>1182$ \\
\hline$(1768,868)$ & - & - & $1768>868$ & $(1266,1095)$ & - & - & $1266>1095$ \\
\hline$(1454,1384)$ & + & 0 & $1454=1384$ & $(1266,955)$ & - & 0 & $1266=955$ \\
\hline$(1454,1364)$ & + & + & $1454>1364$ & $(1266,921)$ & - & 0 & $1266=921$ \\
\hline$(1454,1266)$ & + & - & $1454<1266$ & $(1266,868)$ & - & - & $1266>868$ \\
\hline$(1454,868)$ & - & + & $1454<868$ & $(1095,955)$ & - & + & $1095<955$ \\
\hline$(1384,1364)$ & + & + & $1384>1364$ & $(1095,921)$ & - & + & $1095<921$ \\
\hline$(1384,1266)$ & + & - & $1384<1266$ & $(1095,868)$ & - & + & $1095<868$ \\
\hline$(1384,1182)$ & + & + & $1382>1182$ & $(955,921)$ & 0 & 0 & $955=921$ \\
\hline$(1384,1095)$ & + & + & $1384>1095$ & $(955,868)$ & + & + & $955>868$ \\
\hline$(1384,955)$ & - & + & $1384<955$ & $(921,868)$ & - & - & $921>868$ \\
\hline$(1384,921)$ & - & + & $1384<921$ & & & & \\
\hline \multicolumn{8}{|c|}{ 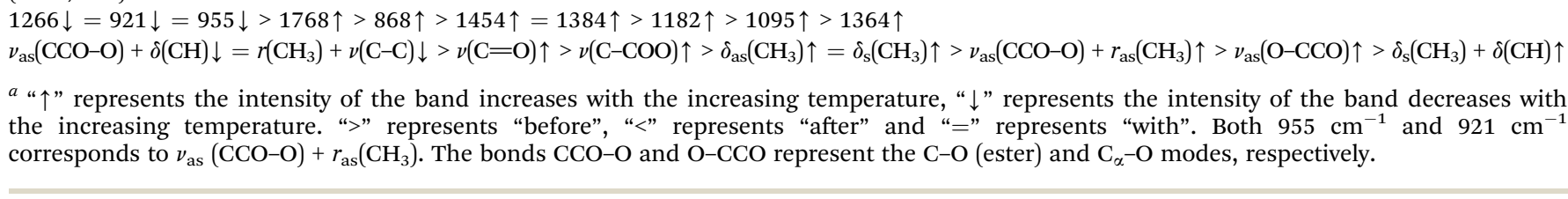 } \\
\hline
\end{tabular}

polymer chains during Process I. In the regularization process, the first molecular movement is $\mathrm{C}=\mathrm{O}$ groups because of the strong polarity and intense interaction with other polar groups. ${ }^{32,33}$ And then the movement of $\mathrm{C}-\mathrm{C}$ backbones takes place. Thirdly, the side methyl groups regularly arrange because of the higher mobility.

Subsequently, the macromolecular motion of the regularization is the ester groups (CO-O). Zhang et al. ${ }^{6-9}$ and Kister et $a .^{10}$ have assigned the bands at about $1182 \mathrm{~cm}^{-1}$ and $1095 \mathrm{~cm}^{-1}$ to $\nu_{\text {as }}(\mathrm{C}-\mathrm{O}-\mathrm{C})$ and $\nu_{\mathrm{s}}(\mathrm{C}-\mathrm{O}-\mathrm{C})$, respectively. However, the ester $\mathrm{CO}-\mathrm{O}-\mathrm{C}$ bonds in ester compounds are in resonance with $\mathrm{C}=\mathrm{O}$ groups and the two $\mathrm{C}-\mathrm{O}$ bonds are no longer identical. Thus, Sarasua et al. ${ }^{\mathbf{1 1 2 4 , 2 6}}$ have referred the bands as the two asymmetrical coupled vibrations: CCO-O (ester) and O$\operatorname{CCO}\left(\mathrm{C}_{\alpha}-\mathrm{O}\right)$ modes. According to the generalized $2 \mathrm{D}$ correlation analysis, the changes of the bands at $1182 \mathrm{~cm}^{-1}$ and $1095 \mathrm{~cm}^{-1}$ are asynchronous which demonstrates that the two $\mathrm{C}-\mathrm{O}$ bonds in ester are different with each other. So in this paper, we referred the $1182 \mathrm{~cm}^{-1}$ and $1095 \mathrm{~cm}^{-1}$ as the CCO-O (ester) and O-CCO $\left(\mathrm{C}_{\alpha}-\mathrm{O}\right)$ modes, respectively, following the results of Sarasua. Finally, the order formation of methyne $(\mathrm{CH})$ is built and the regularization of the whole chain is completed in Process I.

3.3.2 Process II. The generalized 2D correlation FTIR spectra in the region $1899-1650 \mathrm{~cm}^{-1}$ vs. $1899-1650 \mathrm{~cm}^{-1}$ are presented in Fig. 9, which are calculated from the temperaturedependent spectra in Process II (91.1-104.0 ${ }^{\circ} \mathrm{C}$ ) (the generalized 2D correlation FIRT spectra in the regions $1899-1650 \mathrm{~cm}^{-1} v s$. 1549-1300 cm $\mathrm{cm}^{-1}, 1899-1650 \mathrm{~cm}^{-1}$ vs. 1301-1042 $\mathrm{cm}^{-1}$, 1899-1650 $\mathrm{cm}^{-1}$ vs. $996-850 \mathrm{~cm}^{-1}, 1549-1300 \mathrm{~cm}^{-1}$ vs. 1549-1300 $\mathrm{cm}^{-1}, \quad 1549-1300 \mathrm{~cm}^{-1}$ vs. 1301-1042 $\mathrm{cm}^{-1}$, 1549-1300 $\mathrm{cm}^{-1}$ vs. 996-850 $\mathrm{cm}^{-1}, 1301-1042 \mathrm{~cm}^{-1}$ vs. 1301-1042 $\mathrm{cm}^{-1}, 1301-1042 \mathrm{~cm}^{-1}$ vs. 996-850 $\mathrm{cm}^{-1}$, and 996-850 $\mathrm{cm}^{-1}$ vs. $996-850 \mathrm{~cm}^{-1}$ are shown in Fig. S7-S9†). The signs of the correlation peaks during Process II are summarized in Table 5. According to Noda's rule, the sequential order is $1088 \downarrow>1749 \downarrow>1193 \uparrow>1760 \uparrow>1109 \uparrow>1379 \downarrow>1266 \downarrow=921$ $\uparrow=955 \downarrow>1359 \uparrow>871 \uparrow>1458 \uparrow=1389 \uparrow$. Thus, the corresponding sequential order of groups is $\nu_{\text {as }}(\mathrm{O}-\mathrm{CCO}) \downarrow>\nu(\mathrm{C}=\mathrm{O}) \downarrow$ $>\nu_{\mathrm{as}}(\mathrm{CCO}-\mathrm{O})+r_{\mathrm{as}}\left(\mathrm{CH}_{3}\right) \uparrow>\nu(\mathrm{C}=\mathrm{O}) \uparrow>\nu_{\mathrm{as}}(\mathrm{O}-\mathrm{CCO}) \uparrow>\delta_{\mathrm{s}}\left(\mathrm{CH}_{3}\right) \downarrow$ $>\nu_{\mathrm{as}}(\mathrm{CCO}-\mathrm{O})+\delta(\mathrm{CH}) \downarrow=r\left(\mathrm{CH}_{3}\right)+\nu(\mathrm{C}-\mathrm{C}) \uparrow=r\left(\mathrm{CH}_{3}\right)+\nu(\mathrm{C}-\mathrm{C}) \downarrow>$ $\delta_{\mathrm{s}}\left(\mathrm{CH}_{3}\right)+\delta(\mathrm{CH}) \uparrow>\nu(\mathrm{C}-\mathrm{COO}) \uparrow>\delta_{\mathrm{as}}\left(\mathrm{CH}_{3}\right) \uparrow=\delta_{\mathrm{s}}\left(\mathrm{CH}_{3}\right) \uparrow$.

In the cold-crystallization (Process II), the first step of the molecular movement is the $\mathrm{O}-\mathrm{CCO}\left(\mathrm{C}_{\alpha}-\mathrm{O}\right)$ and $\mathrm{C}=\mathrm{O}$ groups in the amorphous phase or interphase. ${ }^{7,11,34,35}$ The two groups existing in the irregular polymer conformations are largely decreased and the movement of O-CCO groups is prior to that of $\mathrm{C}=\mathrm{O}$ groups. Then, the ester groups $(\mathrm{CO}-\mathrm{O}-\mathrm{C})$ are regularly rearranged. The sequential order of the ester regularization is CCO-O (ester) groups before carbonyl groups before O-CCO 
Synchronous

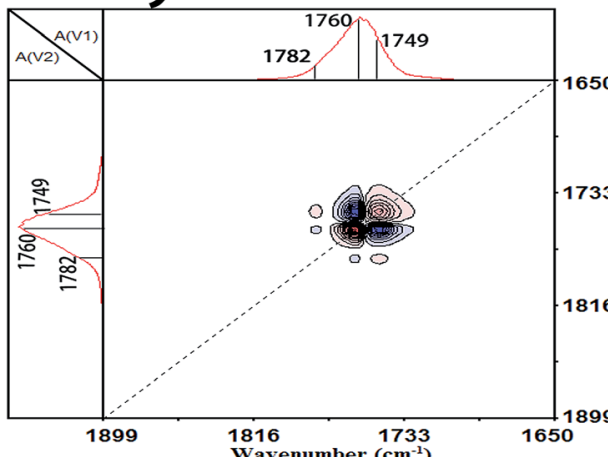

Asynchronous

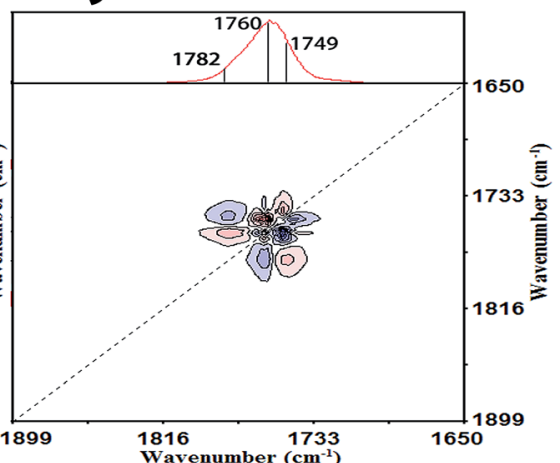

Fig. 9 Synchronous (left) and asynchronous (right) 2D correlation FTIR spectra calculated from the temperature-dependent spectra of Process II $\left(91.1-104.0^{\circ} \mathrm{C}\right.$ ) in the region $1899-1650 \mathrm{~cm}^{-1}$ vs. $1899-1650 \mathrm{~cm}^{-1}$.

Table 5 Sequential order of the PLLA bands and their cross regions in Process II

\begin{tabular}{|c|c|c|c|c|c|c|c|}
\hline $\begin{array}{l}\text { Cross correlation } \\
\text { peak }\left(\mathrm{cm}^{-1}\right)\end{array}$ & $\begin{array}{l}\text { Sign in } \\
\text { synchronous } \\
\text { spectra }\end{array}$ & $\begin{array}{l}\text { Sign in } \\
\text { asynchronous } \\
\text { spectra }\end{array}$ & $\begin{array}{l}\text { Sequential } \\
\text { order }\end{array}$ & $\begin{array}{l}\text { Cross correlation } \\
\text { peak }\left(\mathrm{cm}^{-1}\right)\end{array}$ & $\begin{array}{l}\text { Sign in } \\
\text { synchronous } \\
\text { spectra }\end{array}$ & $\begin{array}{l}\text { Sign in } \\
\text { asynchronous } \\
\text { spectra }\end{array}$ & $\begin{array}{l}\text { Sequential } \\
\text { order }\end{array}$ \\
\hline$(1760,1458)$ & + & + & $1760>1458$ & $(1389,921)$ & - & + & $1389<921$ \\
\hline$(1760,1389)$ & + & + & $1760>1389$ & $(1389,871)$ & - & + & $1389<871$ \\
\hline$(1760,1379)$ & - & - & $1760>1379$ & $(1379,1359)$ & - & - & $1379>1359$ \\
\hline$(1760,1193)$ & + & - & $1760<1193$ & $(1379,1109)$ & - & + & $1379<1109$ \\
\hline$(1760,1109)$ & + & + & $1760>1109$ & $(1379,1088)$ & + & - & $1379<1088$ \\
\hline$(1760,1088)$ & - & + & $1760<1088$ & $(1379,955)$ & + & + & $1379>955$ \\
\hline$(1760,955)$ & - & - & $1760>955$ & $(1379,921)$ & - & - & $1379>921$ \\
\hline$(1760,921)$ & + & + & $1760>921$ & $(1379,871)$ & - & - & $1379>871$ \\
\hline$(1760,871)$ & + & + & $1760>871$ & $(1359,1266)$ & - & + & $1359<1266$ \\
\hline$(1749,1266)$ & + & + & $1749>1266$ & $(1359,921)$ & + & - & $1359<921$ \\
\hline$(1749,1193)$ & - & - & $1749>1193$ & $(1359,871)$ & + & + & $1359>871$ \\
\hline$(1749,1109)$ & - & - & $1749>1109$ & $(1266,1193)$ & - & + & $1266<1193$ \\
\hline$(1749,1088)$ & + & - & $1749<1088$ & $(1266,1109)$ & - & + & $1266<1109$ \\
\hline$(1749,955)$ & + & + & $1749>955$ & $(1266,1088)$ & + & - & $1266<1088$ \\
\hline$(1749,921)$ & - & - & $1749>921$ & $(1266,955)$ & + & 0 & $1266=955$ \\
\hline$(1749,871)$ & - & - & $1749>871$ & $(1266,921)$ & - & 0 & $1266=921$ \\
\hline$(1458,1389)$ & + & 0 & $1458=1389$ & $(1266,871)$ & - & - & $1266>871$ \\
\hline$(1458,1379)$ & - & + & $1458<1379$ & $(1193,1109)$ & + & + & $1193>1109$ \\
\hline$(1458,1359)$ & + & - & $1458<1359$ & $(1193,1088)$ & - & + & $1193<1088$ \\
\hline$(1458,1266)$ & - & + & $1458<1266$ & $(1193,955)$ & - & - & $1193>955$ \\
\hline$(1458,1193)$ & + & - & $1458<1193$ & $(1193,921)$ & + & + & $1193>921$ \\
\hline$(1389,1109)$ & - & + & $1389<1109$ & $(955,871)$ & - & - & $955>871$ \\
\hline$(1389,1088)$ & - & + & $1389<1088$ & $(921,871)$ & + & + & $921>871$ \\
\hline
\end{tabular}


$\left(\mathrm{C}_{\alpha}-\mathrm{O}\right)$ groups. Thirdly, the amorphous methyl groups $\left(\mathrm{CH}_{3}\right)$ begin to diffuse into the regular phase and the $\mathrm{CH}_{3}$ groups among different PLLA chains are in close contact. ${ }^{6}$ Fourthly, the $\mathrm{CCO}-\mathrm{O}$ groups combined with $\mathrm{CH}$ groups sensitive to the amorphous phase are heavily decreased. And simultaneously, large numbers of $10_{3}$ helical chains which are the major component of PLLA $\alpha$ crystals are formed. This demonstrates that the crystallization degree of PLLA is rapidly increased in this primary cold-crystallization process. The final step is the perfection process of $10_{3}$ helical chains. The $\mathrm{CH}$ groups, $\mathrm{C}-\mathrm{C}$ backbones, and $\mathrm{CH}_{3}$ groups locating in the $10_{3}$ helical chains are orderly rearranged to build the more perfect $10_{3}$ helical chains and crystals.

\section{Conclusion}

In this paper, the temperature-dependent FTIR spectroscopy combined with the perturbation correlation moving-window two-dimensional (PCMW2D) spectroscopy and generalized two-dimensional correlation (2D) spectroscopy was applied to investigate the cold-crystallization process of poly(L-lactic acid) (PLLA). Two temperature regions of $60.8-73.7{ }^{\circ} \mathrm{C}$ and 91.1$104.0{ }^{\circ} \mathrm{C}$ are detected via the combination of PCMW2D and differential scanning calorimetry (DSC) measurements. These two temperature regions are defined as Process I (the relaxation process) and Process II (the primary cold-crystallization process), respectively. As FTIR spectroscopy is sensitive to local molecular environment presenting the vibration of shortrange structure, the bands at $1760,1458,1193$, and $1133 \mathrm{~cm}^{-1}$ previously assigned to crystalline sensitive bands are proposed to be regular conformation sensitive bands, like the band of $921 \mathrm{~cm}^{-1}$. Therefore, the intensity of the bands directly reveals the ordering degree of PLLA rather than the crystalline degree. The regularization enthalpy of the PLLA function groups is calculated from van't Hoff plots. During both Process I and Process II, the regularization enthalpy of $\mathrm{C}=\mathrm{O}$ is higher than that of $\mathrm{CH}_{3}$ groups, however, lower than that of $\mathrm{CCO}-\mathrm{O}$ groups. This illustrates that the regularization enthalpy of chemical groups is decreased with their increasing mobility. Furthermore, the regularization enthalpy of all the chemical groups in Process II is much larger than that in Process I. Powerful generalized 2D correlation analysis was applied to study the sequential order of the movement of the chain segments during the cold-crystallization process. It was found that Process I undergoes 2 steps and Process II undergoes 5 steps. For Process I, the first step is the relaxation of the random packed $10_{3}$ helical chains frozen in the glassy state and the decrease of the amorphous ester and methyne groups. The second step is the regularization of polymer chains. The sequential order of group movements in the regularization process is $\nu(\mathrm{C}=\mathrm{O}) \uparrow>$ $\nu(\mathrm{C}-\mathrm{COO}) \uparrow>\delta_{\text {as }}\left(\mathrm{CH}_{3}\right) \uparrow=\delta_{\mathrm{s}}\left(\mathrm{CH}_{3}\right) \uparrow>\nu_{\text {as }}(\mathrm{CCO}-\mathrm{O})+r_{\text {as }}\left(\mathrm{CH}_{3}\right) \uparrow>$ $\nu_{\text {as }}(\mathrm{O}-\mathrm{CCO}) \uparrow>\delta_{\mathrm{s}}\left(\mathrm{CH}_{3}\right)+\delta(\mathrm{CH}) \uparrow$. The changes of the bands at $1182 \mathrm{~cm}^{-1}$ and $1095 \mathrm{~cm}^{-1}$ are asynchronous which demonstrates that the $1182 \mathrm{~cm}^{-1}$ and $1095 \mathrm{~cm}^{-1}$ correspond to the $\mathrm{CCO}-\mathrm{O}$ (ester) and $\mathrm{O}-\mathrm{CCO}\left(\mathrm{C}_{\alpha}-\mathrm{O}\right)$ modes, respectively. For Process II, the first step is the decrease of the amorphous $\mathrm{O}-\mathrm{CCO}\left(\mathrm{C}_{\alpha}-\mathrm{O}\right)$ and $\mathrm{C}=\mathrm{O}$ groups. The second step is rearrangement of the ester groups. The third step is the close contact of $\mathrm{CH}_{3}$ groups among different PLLA chains. The fourth step is the formation of $10_{3}$ helical chains and the fifth step is the perfection process.

\section{Conflicts of interest}

There are no conflicts of interest to declare.

\section{References}

1 D. Lorenzo, Eur. Polym. J., 2005, 41, 569-575.

2 P. De Santis and A. J. Kovacs, Biopolymers, 1968, 6, 229-306.

3 W. Hoogsteen, A. R. Postema, A. J. Pennings, G. T. Brinke and P. Zugenmaier, Macromolecules, 1990, 23, 634-642.

4 B. Eling, S. Gogolewski and A. J. Pennings, Polymer, 1982, 23, 1587-1593.

5 L. Cartier, T. Okihara, Y. Ikada, H. Tsuji, J. Puiggali and B. Lotz, Polymer, 2000, 41, 8909-8919.

6 J. Zhang, H. Tsuji, I. Noda and Y. Ozaki, J. Phys. Chem. B, 2004, 108, 11514-11520.

7 J. Zhang, H. Tsuji, I. Noda and Y. Ozaki, Macromolecules, 2004, 37, 6433-6439.

8 J. Zhang, Y. Duan, H. Sato, H. Tsuji, I. Noda, S. Yan and Y. Ozaki, Macromolecules, 2005, 38, 8012-8021.

9 J. Zhang, C. Li, Y. Duan, A. J. Domb and Y. Ozaki, Vib. Spectrosc., 2010, 53, 307-310.

10 G. Kister, G. Cassanas and M. Vert, Polymer, 1998, 39, 267273.

11 E. Meaurio, N. Lopez-Rodriguez and J. R. Sarasua, Macromolecules, 2006, 39, 9291-9301.

12 I. Noda, Appl. Spectrosc., 1993, 47, 1329-1336.

13 M. Thomas and H. H. Richardson, Vib. Spectrosc., 2000, 24, 137-146.

14 S. Morita, H. Shinzawa, I. Noda and Y. Ozaki, Appl. Spectrosc., 2006, 60, 398-406.

15 J. Zhang, H. Sato, H. Tsuji, I. Noda and Y. Ozaki, Macromolecules, 2005, 38, 1822-1828.

16 J. Zhang, Y. Duan, A. J. Domb and Y. Ozaki, Macromolecules, 2010, 43, 4240-4246.

17 J. Zhang, K. Tashiro, H. Tsuji and A. J. Domb, Macromolecules, 2008, 41, 1352-1357.

18 K. Wasanasuk and K. Tashiro, Macromolecules, 2011, 44, 9650-9660.

19 T. Zhou, A. Zhang, C. Zhao, H. Liang, Z. Wu and J. Xia, Macromolecules, 2007, 40, 9009-9017.

20 A. Savitzky and M. J. E. Golay, Anal. Chem., 1964, 36, 16271639.

21 G. Su, T. Zhou, Y. Zhang, X. Liu and A. Zhang, Soft Matter, 2016, 12, 1145-1157.

22 I. M. Hodge, Macromolecules, 1983, 16, 898-902.

23 A. R. Berens and I. M. Hodge, Macromolecules, 1982, 15, 756761.

24 E. Meaurio, E. Zuza, N. Lopez-Rodriguez and J. R. Sarasua, J. Phys. Chem. B, 2006, 110, 5790-5800.

25 G. Su, T. Zhou, X. Liu, J. Zhang, J. Bao and A. Zhang, RSC Adv., 2015, 5, 84729-84745. 
26 J. Sarasua, N. L. Rodriguez, A. L. Arraiza and E. Meaurio, Macromolecules, 2005, 38, 8362-8371.

27 L. Qin, J. Qiu, M. Liu, S. Ding, L. Shao, S. Lu, G. Zhang, Y. Zhao and X. Fu, Chem. Eng. J., 2011, 166, 772-778.

28 D. F. Swinehart, J. Chem. Educ., 1962, 39, 333.

29 Q. Yuan, T. Zhou, L. Li, J. Zhang, X. Liu and X. Ke, RSC Adv., 2015, 5, 31153-31165.

30 P. J. Pan, B. Zhu, W. H. Kai, T. Dong and Y. Inoue, Macromolecules, 2008, 41, 4296-4304.
31 H. Urayama, S. Moon and Y. Kimura, Macromol. Mater. Eng., 2003, 288, 137-143.

32 P. J. Pan, B. Zhu and Y. Inoue, Macromolecules, 2007, 40, 9664-9671.

33 S. Kang, S. L. Hsu, H. D. Stidham, P. B. Smith, M. A. Leugers and X. Yang, Macromolecules, 2001, 34, 4542-4548.

34 J. Dlouha, L. Suryanegara and H. Yano, Soft Matter, 2012, 8, 8704-8713.

35 H. Mao, G. Shan, Y. Bao, Z. L. Wu and P. Pan, Soft Matter, 2016, 12, 4628-4637. 